\title{
Managing Hypoxemia During Minimally Invasive Thoracic Surgery
}

Jens Lohser, MD, MSc, FRCPC

\section{KEYWORDS}

- Hypoxemia • One-lung ventilation • Thoracoscopy

\section{KEY POINTS}

- An ever-increasing number of thoracic procedures are being performed through minimally invasive techniques.

- Although the incidence of hypoxemia during one-lung ventilation (OLV) has decreased over the years, it remains an issue in roughly $10 \%$ of cases.

- Algorithms for the management of OLV hypoxemia have to be adapted to the thoracoscopic approach, in particular the need for optimal surgical exposure.

- With appropriate planning and caution most of the treatment modalities for OLV hypoxemia can be applied to the thoracoscopy setting with some modifications.

\section{INTRODUCTION}

Minimally invasive approaches are gradually replacing most open surgical procedures. After being introduced into thoracic surgery as a diagnostic modality a century ago, ${ }^{1}$ both video-assisted thoracoscopic surgery (VATS) and robot-assisted thoracoscopic surgery have since been described for every aspect of thoracic surgery: esophageal resections, mediastinal surgery, and all types of lung resections, including pneumonectomies. ${ }^{2}$ The reported clinical benefits of VATS are perioperative decreases in blood loss, pain, inflammatory response, chest tube duration, and atrial fibrillation as well as improved postoperative pulmonary function and length of hospitalization. ${ }^{3-5}$ Although operating room times tend to be increased for video-assisted procedures, the overall hospital costs are lower, which supports its widespread implementation. ${ }^{3}$ Oncologic results seem to be equivalent to the open approach; however, few randomized studies have examined this aspect. ${ }^{6,7}$

Surgical exposure has traditionally been viewed as only a relative indication for lung isolation in thoracotomy procedures. In contrast, operative lung isolation or collapse is

\footnotetext{
Department of Anesthesiology, Pharmacology and Therapeutics, University of British Columbia, Vancouver General Hospital, JPP2 Room 2449, 899 West 12th Avenue, Vancouver, British Columbia, V5Z-1M9, Canada

E-mail address: jens.lohser@vch.ca
} 
essential to the successful performance of thoracoscopic procedures. ${ }^{8}$ Hypoxemia used to be the primary concern associated with the provision of one-lung ventilation (OLV). However, its incidence has decreased significantly over the years, likely due to the increased use of fiberoptic bronchoscopy for confirmation of lung isolation and the use of anesthetic agents with less effect on hypoxic pulmonary vasoconstriction (HPV). ${ }^{9}$ There has been some uncertainty in the literature on the true incidence of hypoxemia, in part because of its nonuniform definition and the large variability in reporting thresholds. Electronic medical records seem to indicate a higher rate of hypoxemia than that documented in manually recorded charts. ${ }^{10}$ Clinically meaningful hypoxemia probably continues to occur in roughly $10 \%$ of patients during OLV.

\section{THORACOSCOPY: WHAT IS DIFFERENT?}

Whether surgery is performed through trocar sites or a full thoracotomy incision is immaterial to the redistribution of pulmonary blood flow by gravity and HPV. Similarly, the effect of lung isolation and OLV on the alteration of lung compliance and redistribution of ventilation is no different between open and closed approaches. The physiologic changes of OLV are beyond the scope of this article and have been reviewed in detail. $^{9,11}$

The thoracic cavity remains partially closed during VATS procedures, because the incisions are essentially sealed by trocars and surgical instruments. This fact results in several pressure-related effects that distinguish thoracoscopic from open procedures. Although insertion of the trocars does breach the pleural interface, the presence of the instruments restricts the air inflow that is necessary for development of the surgical pneumothorax. Lung collapse is therefore delayed and often incomplete unless aided by applying suction to the open airway or facilitating air entry into the thorax by opening one of the trocars. The rate of lung collapse is maximal if OLV is preceded by complete denitrogenation. ${ }^{12}$ Surgical suctioning reexpands the operative lung by creating negative intrathoracic pressure unless a vent is being used to decompress the hemithorax. Conversely, $\mathrm{CO}_{2}$ insufflation, which is sometimes used to improve visualization, creates tamponade physiology at moderately low insufflation pressures of 5 to $15 \mathrm{~mm} \mathrm{Hg} .^{13}$ The main indication for the use of $\mathrm{CO}_{2}$ insufflation is the inability to establish lung isolation (secondary to unfavorable airway anatomy or lack of appropriately sized device), which is why it is unusual outside of pediatric practice.

OLV management of the down-lung is unchanged from the thoracotomy settings and should focus on maintaining functional residual capacity (FRC) and open lung. ${ }^{9}$ Because of the need for complete lung collapse for surgical exposure, techniques that involve partial or complete insufflation (continuous positive airway pressure [CPAP]) or ventilation (high-frequency jet ventilation [HFJV], two-lung ventilation [TLV]) of the operative lung are considered relatively contraindicated.

Surgical access to the lung is restricted, which complicates some of the interventions that have been described for the treatment of hypoxemia during thoracotomy procedures. Although mechanical restriction of the shunt fraction is still possible, it is significantly more difficult than in the open scenario. Lung retraction is feasible for the surgeons, whereas packing of the lung, which has been shown to improve shunt fraction, ${ }^{14}$ is not. In the setting of refractory hypoxemia, the shunt fraction can be reduced by side-clamping the pulmonary artery (PA) or by distorting the PA anatomy with a sponge stick, both of which are feasible during thoracoscopy but more difficult than during open procedures.

What is not different between VATS and open procedures is the amount of intrathoracic trauma. External tissue trauma is reduced, resulting in improved postoperative 
lung function and earlier hospital discharge times. However, the intrathoracic surgical trauma is unchanged from the open approach, and there is "... no lessening in the complexity of the anesthetic process, [and] the degree of physiological trespass...."1 One needs to guard against the perception that procedures are just thoracoscopy, because there is no similarity between a VATS lobectomy and a VATS bullectomy in terms of the amount of tissue and vasculature that have to be resected and the potential for perioperative and immediate postoperative complications.

\section{PREDICTORS FOR HYPOXEMIA DURING OLV}

The physiologic changes associated with OLV for ventilation or perfusion during thoracoscopy are no different to those encountered during open thoracotomy. The predictors of hypoxemia for OLV are therefore unchanged from the open procedure (Table 1).

\section{PREVENTATIVE MEASURES TO AVOID HYPOXEMIA}

Because of the limited ability to use the operative lung for apneic oxygenation or ventilation, prevention of hypoxemia is crucial. Impaired HPV caused by hypocapnea, vasodilators, or excessive volatile anesthesia has to be avoided. Any shunt in the ventilated lung, because of derecruitment, is poorly tolerated. Appropriate and individualized ventilator settings focused on open-lung ventilation are essential (Table 2). ${ }^{9}$

The concept of open-lung ventilation originated in the intensive care literature and is an evolution of the management of patients with acute respiratory distress syndrome (ARDS). It consists of avoidance of cycling recruitment and derecruitment for lung injury prevention. In addition, open-lung ventilation maintains FRC and optimizes ventilation/perfusion (V/Q) matching and $\mathrm{CO}_{2}$ elimination in the ventilated lung. ${ }^{15,16}$ Although the shunt fraction primarily depends on the amount of perfusion through the collapsed operative lung, any additional shunt through the ventilated lung in excess of the physiologic $5 \%$ is poorly tolerated and usually preventable.

Derecruitment is a common reason for desaturation during OLV. The dependent ventilated lung is noncompliant because of extrinsic compression by abdominal and mediastinal contents and may be inadequately distended by low-tidal volume ventilation with insufficient positive end-expiratory pressure (PEEP). Application of a manual recruitment or vital capacity maneuver at a pressure of 30 to $40 \mathrm{~cm} \mathrm{H}_{2} \mathrm{O}$ has been shown to result in improved oxygenation during OLV. ${ }^{15}$ Prolonged application of a vital capacity maneuver results in a reduced cardiac output, which routinely manifests as a transient dip in oxygen saturations, but may also result in significant hemodynamic instability. ${ }^{17,18}$ When using a double-lumen tube (DLT), recruitment can be selectively applied to one lung at a time, which minimizes the intrathoracic pressure increase and associated hemodynamic effects. ${ }^{19}$ Invasive arterial monitoring is beneficial for any

\begin{tabular}{|c|c|}
\hline $\begin{array}{l}\text { Table } 1 \\
\text { Predictors of OLV hypoxemia }\end{array}$ & \\
\hline Patient & Procedure \\
\hline $\begin{array}{l}\text { Preferential perfusion to operative lung } \\
\circ \quad \text { Previous contralateral resection } \\
\end{array}$ & $\begin{array}{l}\text { Preferential perfusion to operative lung } \\
\circ \quad \text { Right-sided surgery } \\
\end{array}$ \\
\hline Normal FEV 1 & Supine position \\
\hline Chronic vasodilator therapy & Vasodilator use \\
\hline Poor oxygenation on TLV & Excessive volatile anesthesia ( $>>1 \mathrm{MAC}$ ) \\
\hline
\end{tabular}

Abbreviations: $\mathrm{FEV}_{1}$, forced expiratory volume in first second of expiration; MAC, minimum alveolar concentration. 


\begin{tabular}{|c|c|c|c|}
\hline & Traditional OLV & Protective OLV & Comments \\
\hline Emphasis & Oxygenation & $\begin{array}{l}\text { Acute lung injury } \\
\text { avoidance }\end{array}$ & \\
\hline $\mathrm{FlO}_{2}$ & 1.0 & $0.5-0.8$ & $\begin{array}{l}\text { Titrate as tolerated to stable } \\
\mathrm{SpO}_{2}>90 \%\end{array}$ \\
\hline $\mathrm{Vt}$ & $10 \mathrm{~mL} / \mathrm{kg}$ & $4-6 \mathrm{~mL} / \mathrm{kg}$ & $\begin{array}{r}\text { Consider larger Vt if } \\
\text { refractory hypoxia }\end{array}$ \\
\hline $\mathrm{PCO}_{2}$ & $40 \mathrm{~mm} \mathrm{Hg}$ & $40-60 \mathrm{~mm} \mathrm{Hg}$ & $\begin{array}{l}\text { Cardiovascular instability } \\
\text { possible at } \mathrm{PCO}_{2}>70 \mathrm{~mm} \mathrm{Hg}\end{array}$ \\
\hline PEEP & None & $5-10 \mathrm{~cm} \mathrm{H}_{2} \mathrm{O}$ & \\
\hline Ventilator mode & Volume control & Pressure regulated & Consider HFJV \\
\hline
\end{tabular}

Abbreviations: Vt, tidal volume.

recruitment maneuver in excess of 10 to 20 seconds. Recruitment maneuvers are successful in achieving improved oxygenation if atelectasis was present in the ventilated lung. This situation by definition indicates that ventilation, and in particular the amount of PEEP, was insufficient to prevent lung collapse. A positive recruitment maneuver should lead to an increase in the applied PEEP. A negative response may indicate adequate or excessive PEEP levels. Excessive PEEP may create or worsen air trapping in predisposed patients. ${ }^{20}$ Dynamic air trapping may lead to hypotension because of pulmonary tamponade and can be detected by the presence of residual expiratory flow at the onset of inspiration (Fig. 1). ${ }^{21}$

Depressed cardiac output because of neuraxial anesthesia, excessive depth of anesthesia, or tamponade physiology from $\mathrm{CO}_{2}$ insufflation impairs mixed venous oxygen concentrations, which is difficult to overcome in the setting of high shunt caused by OLV. Restoration of normal cardiac output with inotropic agents (eg, ephedrine) may be required.

\section{TREATMENT OF HYPOXEMIA DURING THORACOSCOPY}

The primary reason for desaturation is high shunt flow through the nonventilated lung. Resumption of TLV is therefore the most effective way to address the hypoxemia.

A

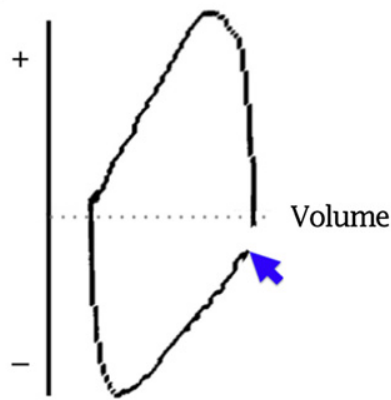

B

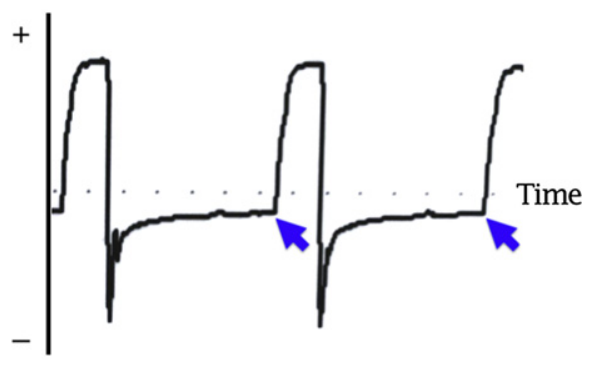

Flow

Fig. 1. Evidence of air trapping on spirometry. A flow-volume loop $(A)$ and a flow-time trace $(B)$ show that inspiration begins before complete exhalation of the previous breath (b/ue arrow), leading to gas trapping. 
However, because TLV usually impairs exposure to the point that surgery has to be interrupted, other treatment modalities need to be considered unless hypoxemia is severe.

Hypoxemia during thoracoscopy should be addressed in stages (Fig. 2). First, any scenario should be temporized with increasing $\mathrm{FIO}_{2}$ (fraction of inspired oxygen) and ensuring adequate hemodynamics. Immediate recruitment of the operative lung may be required, in cases of severe or symptomatic hypoxemia. With the situation temporized, the initial approach to hypoxemia during OLV is directed toward ensuring optimal ventilation of the nonoperative lung and appropriate circulatory parameters to support oxygen delivery. If hypoxemia persists, advanced interventions to manipulate pulmonary blood flow or use of the operative lung for oxygenation can be entertained.

Lower $\mathrm{FIO}_{2}$ has become routine in light of concerns about oxygen toxicity and potential acute lung injury (ALI). ${ }^{9}$ However, high $\mathrm{FIO}_{2}$ is clearly required in the setting of hypoxemia, both to increase oxygen delivery and to act as a pulmonary vasodilator, ${ }^{22}$ which may improve $V / Q$ matching.

Whenever hypoxemia occurs, it is important to ensure right ventricular (RV) perfusion. HPV in response to OLV increases RV workload because of the increase in the pulmonary vascular resistance (PVR) in the operative lung. ${ }^{23}$ Hypoxemia places further stress on the RV because of global pulmonary vascular constriction. Increasing RV systolic pressures cause gradual reductions in RV myocardial perfusion and can result in RV failure as a result of ischemia of the RV free wall. Systemic hypotension is poorly tolerated during periods of RV strain, because effective RV contraction depends on both the rigidity of the interventricular septum as support and the adequacy of the coronary perfusion pressure. ${ }^{24}$ Systemic blood pressure support with inotropic agents

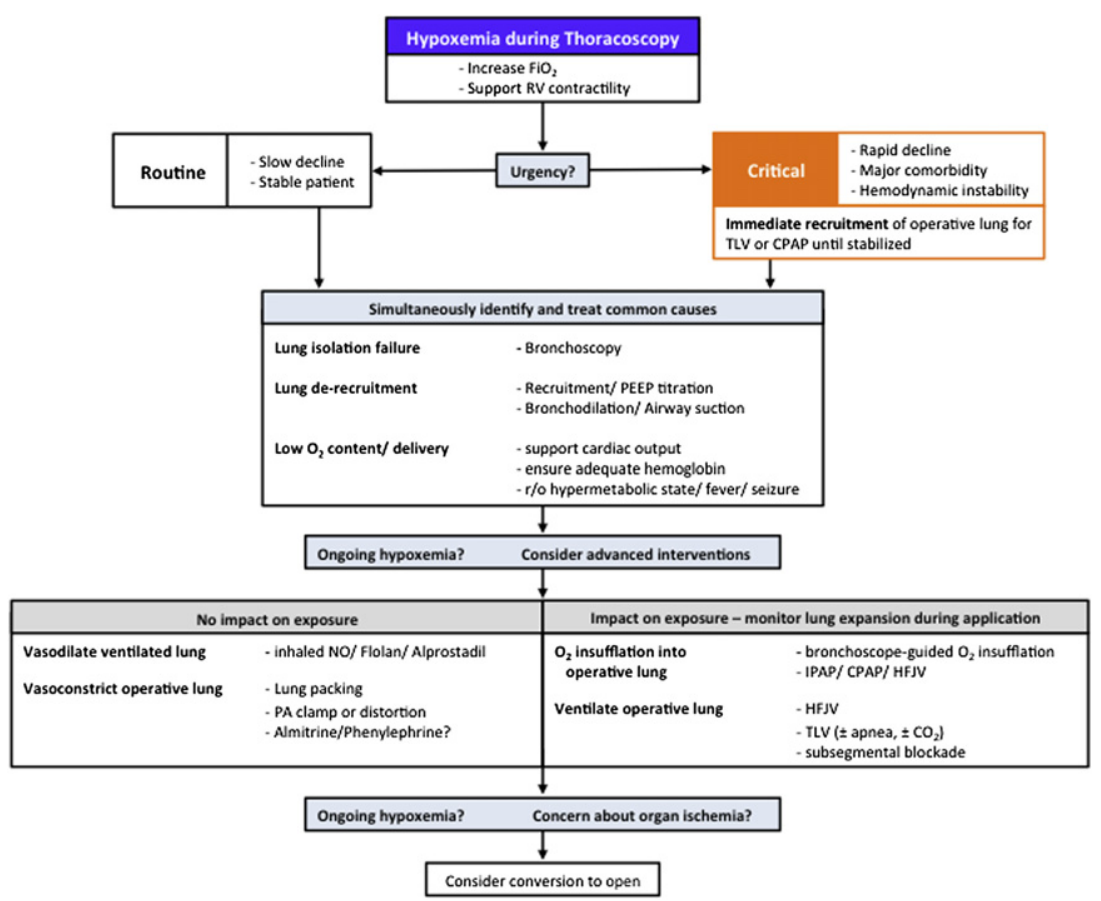

Fig. 2. OLV hypoxemia treatment pathway adapted to thoracoscopic surgery. See text for details. IPAP, intermittent positive airway pressure; NO, nitric oxide; PEEP, positive endexpiratory pressure; RV, right ventricular. 
increases RV perfusion and contractility, and therefore the ability of the RV to cope with high afterload conditions. ${ }^{24,25}$

Rather than being a simple function of the degree of desaturation, the urgency of intervention is largely a judgment call based on the specific situation. A saturation of $88 \%$ to $90 \%$ may be inconsequential and well tolerated for a short wedge resection and in some cases may represent the baseline saturation in patients with advanced chronic obstructive pulmonary disease. On the other hand, a saturation of $90 \%$ to $94 \%$ may be insufficient in a patient with coronary artery disease and acute electrocardiographic changes or a patient with cerebrovascular disease and decreases in cerebral oximetry. Symptomatic hypoxemia or sudden severe hypoxemia should be stabilized with (at least transient) TLV.

\section{IDENTIFY AND TREAT COMMON CAUSES}

The first phase of hypoxemia assessment and treatment focuses on optimal ventilation of the nonoperative lung and appropriate circulatory parameters to support oxygen delivery. Loss of lung isolation, especially partial obstruction of the ventilated bronchus, results in hypoventilation and derecruitment. Lung isolation therefore needs to be confirmed as part of any assessment of OLV hypoxia. The need for fiberoptic bronchoscopy for confirmation depends on the clinical scenario and the index of suspicion for device malposition (ie, the side of surgery, the type of lung isolation device, and the initial adequacy of positioning of the device). In many cases, at least transient confirmation can be achieved by ensuring that ventilator parameters (pressures and volumes) are unchanged. Simultaneously, all ventilator settings should be reviewed to ensure that adequate alveolar ventilation is achieved. As discussed earlier, derecruitment has to be considered as one of the most likely reasons for any desaturation during OLV. Application of a manual recruitment or vital capacity maneuver at a pressure of 30 to $40 \mathrm{~cm} \mathrm{H}_{2} \mathrm{O}$ results in improved oxygenation in most patients. ${ }^{15} \mathrm{~A}$ positive response to a recruitment maneuver should lead to an increase in the applied PEEP. Inadequate oxygen delivery caused by low cardiac output or low hemoglobin concentration must be ruled out. Transfusion is rarely necessary or justified for maintenance of oxygenation. However, cardiac output support is more commonly necessary. Anesthetic agents and neuraxial sympatholytics depress cardiac output, which may not be tolerated in the frail or hypovolemic patient. Avoidance of excessive anesthetic depth and correction of severe hypovolemia often suffices. Occasional support with inotropic agents (eg, ephedrine) may be necessary and helps to minimize fluid administration. Supranormal cardiac outputs are not indicated and may be detrimental for oxygenation. ${ }^{26,27}$ If hypoxemia persists in the face of optimal perfusion and nondependent lung ventilation, advanced interventions may be required. These interventions can consist of manipulations of the shunt fraction, or alternatively, attempts to use the operative lung for oxygenation, the latter of which may interfere with surgical exposure.

\section{ADVANCED INTERVENTIONS WITH NO IMPACT ON EXPOSURE}

OLV results in a disruption of normal V/Q matching. Modulation of pulmonary blood flow, either vasodilation of the ventilated lung to accommodate more blood flow or vasoconstriction of the operative lung to further restrict the shunt fraction, can be attempted to more closely match baseline V/Q matching.

\section{Vasodilators}

The ventilated lung receives roughly $70 \%$ to $80 \%$ of the cardiac output during OLV as a result of gravity redistribution and HPV. The pulmonary vascular bed is capable of 
accepting large increases in blood flow because of its vast recruitable territory. During exercise, cardiac outputs of 30 Liters per minute (Lpm) can be accommodated without increases in pulmonary arterial blood pressure by decreasing PVR. ${ }^{28}$ In theory, reducing PVR in the ventilated lung to accommodate more blood flow and thereby reduce the shunt flow across the nonventilated lung should improve oxygenation. In order to maintain HPV in the operative lung, these vasodilators need to be applied selectively to the ventilated lung, which can be achieved by using the inhalational route. Several inhalational pulmonary vascular dilators have been trialed, but only nitric oxide (NO), alprostadil (PGE1) and prostacyclin (PGl1, also known as epoprostenol or Flolan) have been evaluated in the OLV setting. ${ }^{29}$ Oxygen itself is an effective pulmonary vascular dilator ${ }^{22}$; however, presumably it is already applied at maximal concentrations. Nitric oxide, an endothelium-derived relaxing factor, is a selective pulmonary vascular dilator. It has been shown to decrease PVR and pulmonary artery pressure (PAP) without affecting venous admixture in patients with normal and moderately increased mean PAP. ${ }^{30}$ In studies of patients undergoing thoracic surgery with OLV, inhaled NO (iNO) of 20 ppm was unable to improve oxygenation unless combined with a vasoconstrictor. ${ }^{31}$ This lack of oxygenation benefit was independent of $\mathrm{FlO}_{2} \cdot{ }^{32}$ In a piglet OLV study, an oxygenation benefit could be shown at concentrations of 4 ppm of iNO, but not higher concentrations. ${ }^{33}$ Inhaled prostacyclin (PGI2) has been shown to be as effective as iNO in terms of pulmonary vasodilation in ARDS, cardiac surgery, an animal model of OLV, and lung transplantation. ${ }^{34-36}$ As far as oxygenation is concerned, inhaled prostacyclin showed an $88 \%$ response rate for increases in $\mathrm{PAO}_{2}$ (partial pressure of oxygen, alveolar) $/ \mathrm{FIO}_{2}$ ratio in a diverse population of intensive care unit patients during TLV, ${ }^{37}$ but has not been evaluated for OLV. Alprostadil (PGE1) has a higher pulmonary clearance and therefore fewer systemic effects than prostacyclin. Inhaled PGE1 (10 ng/ $\mathrm{kg} / \mathrm{min}$ ) has been shown to reduce PVR and improve oxygenation (with a decrease in shunt fraction from $25.9 \%$ to $17.4 \%$ ) during firstgraft implantation of double-lung transplants. ${ }^{38}$ As a whole, the prostaglandins are significantly cheaper than NO, both in terms of drug cost and delivery system, and provide significant hospital savings. ${ }^{39}$ In light of the variable efficacy and significant time required for setup of drug-delivery systems, inhaled agents cannot be relied on as a sudden rescue strategy; their use usually requires advance planning and preparation in the high-risk surgical candidate.

\section{Vasoconstrictors}

Even with maximal HPV about a quarter of the cardiac output continues to shunt through the nonventilated lung. This deoxygenated fraction mixes with the oxygenated blood from the ventilated lung and impairs arterial oxygen content. Additional decreases in pulmonary blood flow, and therefore the shunt fraction, can be achieved by pharmacologic means. Almitrine, a respiratory stimulant, which acts as a selective pulmonary vasoconstrictor when injected intravenously, has been shown to potentiate HPV and reduce shunt fraction. Moutafis and colleagues ${ }^{40}$ showed that an intravenous infusion of $8 \mu \mathrm{g} / \mathrm{kg} / \mathrm{min}$ of almitrine resulted in a $\mathrm{PAO}_{2}$ of $325 \mathrm{~mm} \mathrm{Hg}$ after 30 minutes of OLV (vs $178 \mathrm{~mm} \mathrm{Hg}$ in a placebo group) without producing any adverse hemodynamic changes. When used in combination with $20 \mathrm{ppm}$ of iNO an intravenous infusion of 16 $\mu \mathrm{g} / \mathrm{kg} / \mathrm{min}$ of almitrine resulted in a $\mathrm{PAO}_{2}$ of $408 \mathrm{~mm} \mathrm{Hg}$ after 30 minutes of OLV (vs 146 $\mathrm{mm} \mathrm{Hg}$ in the control group). ${ }^{31}$ Although almitrine is effective in improving oxygenation, high-dose infusions are associated with increases in PA pressures, ${ }^{41}$ which is a potential safety concern, particularly because most of the published data are from small studies, which excluded patients with preexisting pulmonary hypertension. Almitrine remains a theoretical intervention in North America, where it is not commercially 
available. Other vasoconstrictors have been entertained; however, as none of them are pulmonary specific all result in concomitant systemic vasoconstriction. Phenylephrine infusions have been assessed in a small trial of patients with ARDS. An intravenous infusion of 50 to $200 \mu \mathrm{g} / \mathrm{min}$ did achieve a modest improvement in oxygenation, although only in $50 \%$ of patients, and predictably caused systemic vasoconstriction in all patients. ${ }^{42}$

Not having the benefit of larger studies that clearly establish a dose-response curve, as well as a safety profile, particularly in the patient with preexisting pulmonary hypertension and right heart dysfunction, it is difficult to recommend routine pharmacologic manipulation. Inhaled vasodilators may be entertained in high-risk patients, with alprostadil being the only agent that has been shown to improve oxygenation during OLV. There is no literature support for the use of vasoconstrictors other than almitrine for OLV hypoxemia and any such treatment would likely necessitate more invasive hemodynamic monitoring.

Beyond pharmacologic manipulation, PA flow can be mechanically manipulated. Clamping of the PA has been discussed as an intervention in cases of refractory hypoxemia during OLV. Specific surgical techniques for clamping the PA during VATS have been described. ${ }^{43,44}$ Aside from physically clamping or side-clamping the artery, which requires hilar exposure, simple distortion of the anatomy can be effective in reducing pulmonary blood flow. Ishikawa and colleagues ${ }^{14}$ have shown that packing the lung in the open scenario does improve oxygenation, likely by physically distorting the pulmonary arterial tree. Any reduction in the operative lung pulmonary blood flow comes at the potential cost of increased RV strain. In the study by Ishikawa and colleagues, ${ }^{14}$ lung packing resulted in decreases in cardiac output and oxygen delivery.

\section{ADVANCED INTERVENTIONS WITH POTENTIAL IMPACT ON EXPOSURE}

Partial ventilation, or apneic oxygenation, of the operative lung is well known for thoracotomy procedures but is generally considered contraindicated in the thoracoscopy setting. Partial lung reinflation is required for these techniques in order for oxygen to be delivered past the conducting airway to the alveolar epithelium. However, this reinflation may interfere with surgical exposure. In order to avoid or minimize the impairment of the surgical exposure, reinflation can be limited to a subsegment of the lung that is remote to the surgical site or be minimally applied across the entire lung. Any reinflation must be monitored in real time on the thoracoscopy monitors. The amount of lung distention and the resulting impairment in surgical exposure are largely dependent on the underlying lung disease and the amount of elastic recoil in the lung tissue. After reinflation, oxygen can be delivered via CPAP circuit, fiberoptic bronchoscope, modified oxygen flush, or HFJV.

CPAP to the operative lung is a proven technique for improving oxygenation because it converts shunt lung to (partially) oxygenated lung, which participates in gas exchange. ${ }^{45,46}$ CPAP is considered contraindicated in thoracoscopic procedures because it does require some lung recruitment from the fully atelectatic stage in order to deliver oxygen to the alveoli. In a trial of incremental CPAP titration during open thoracotomy, addition of CPAP resulted in predictable increases in oxygenation without interfering with the surgical field until CPAP pressures of $9 \mathrm{~cm} \mathrm{H}_{2} \mathrm{O}$ were reached. ${ }^{47}$ Low CPAP pressures of $2 \mathrm{~cm} \mathrm{H}_{2} \mathrm{O}$ have been assessed during thoracoscopy and shown to result in minimal if any impairment of the operative field, with surgeons' satisfaction ranking 9 out of $10 .^{48}$ Beyond minimizing the inflation pressure, the amount of lung recruitment has to be limited in order not to impair the surgical field. Patients in whom lung collapse was difficult to achieve or required suction assistance, such as 
those with severe emphysematous disease, are not good candidates for intraoperative recruitment and CPAP. Similarly, surgeons may not be able to tolerate any degree of recruitment during procedures that require perfect hilar exposure (eg, lobectomies).

Various CPAP adaptations have been proposed to allow for oxygen insufflation without impairing surgical exposure. Russell ${ }^{49}$ proposed intermittent positive airway pressurization (IPAP) with oxygen using oxygen tubing attached to a bacteriostatic filter on the nonventilated lumen of the DLT (Fig. 3). Occlusion of the filter end effectively closes the circuit and results in delivery of the set oxygen flow into the nonventilated lung, creating transient positive airway pressure and lung recruitment. Using 2 second inspirations at 2 Lpm oxygen flow 6 times per minute for up to 5 minutes, Russell was able to show a mean increase in $\mathrm{Spo}_{2}$ of $7.2 \%$ in 10 patients during OLV. More importantly, he documented minimal lung motion and no impact on surgical exposure. ${ }^{49}$

$\mathrm{Ku}$ and colleagues ${ }^{50}$ proposed subsegmental IPAP, specifically for the purposes of treating hypoxemia during thoracoscopy (Fig. 4). Using an oxygen source connected to the suction port of a fiberoptic bronchoscope, the investigators delivered IPAP (20 seconds at $5 \mathrm{Lpm}$ ) into a bronchopulmonary segment distant to the operative site (in their case, an apical bullectomy). This approach heavily relies on adequate knowledge of the subsegmental airway anatomy and clear communication with the surgical team. The amount of lung recruitment that occurs with the IPAP techniques depends on the amount of oxygen flow, the underlying lung disease, and the duration of the IPAP insufflation and therefore requires continuous observation on the surgical monitors. The specific oxygen flow rates and inspiratory times in Figs. $\mathbf{3}$ and $\mathbf{4}$ are examples and need to be adapted to the clinical situation.

Simple oxygen insufflation into the bronchus for apneic oxygenation has been described $^{51}$ but does require residual alveolar recruitment. Application of oxygen at the time of complete lung collapse without recruitment does not result in improved oxygenation. $^{52}$

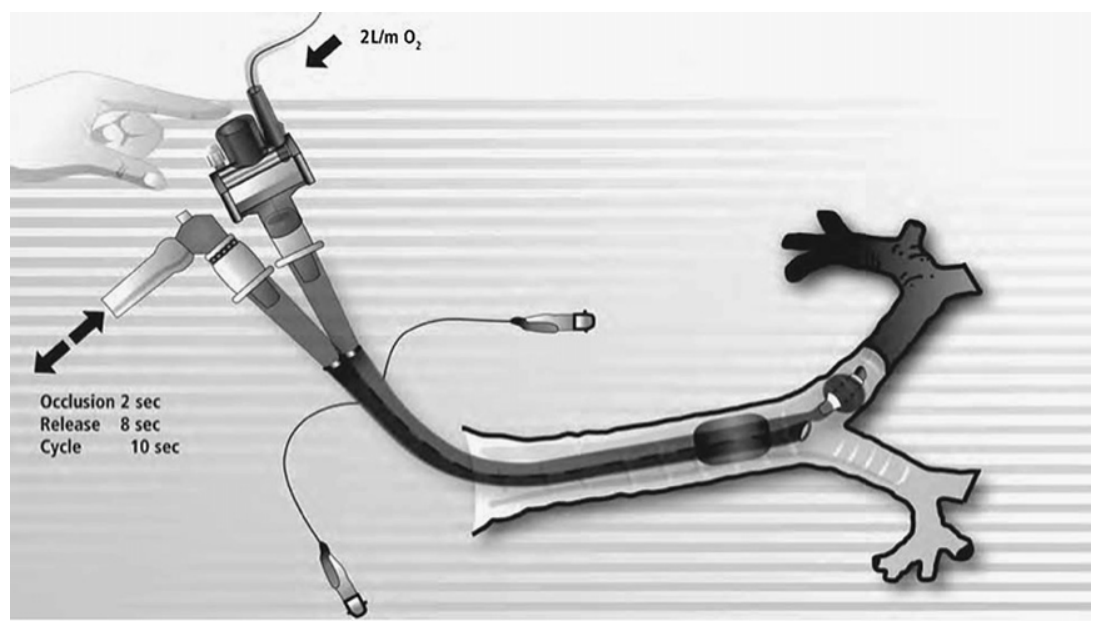

Fig. 3. Schematic representation of the Intermittent Positive Airway Pressure technique. A bacteriostatic filter is attached to the $15-\mathrm{mm}$ connector of the nonventilated DLT lumen. Tubing with an oxygen flow of $2 \mathrm{Lpm}$ is connected to the sampling port of the filter. The open port of the filter is occluded for 2 seconds and open for 8 seconds. See text for details. (Reproduced from Russell WJ. Intermittent positive airway pressure to manage hypoxia during one-lung anaesthesia. Anaesth Intensive Care 2009;37(3):433; with permission.) 


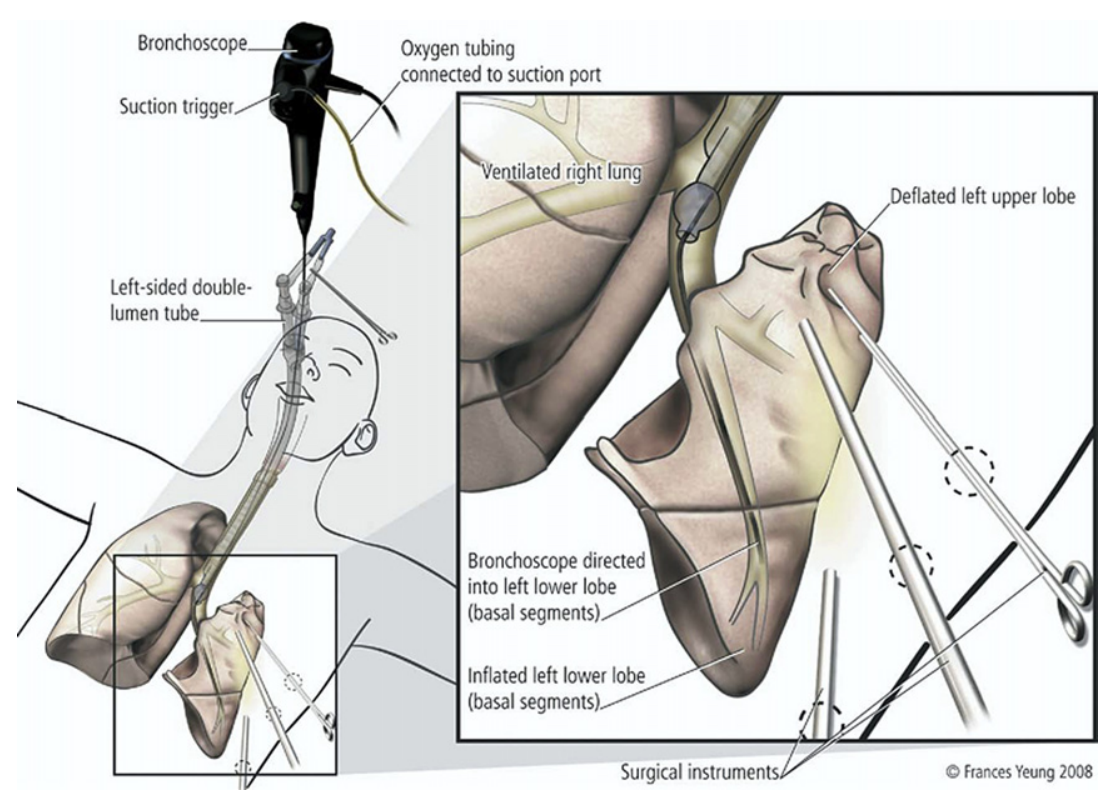

Fig. 4. Bronchoscope-directed segmental oxygen insufflation. The figure demonstrates the technique of insufflating oxygen directly into the left lower lobe basal segments using a fiberoptic bronchoscope during left-sided apical VATS bullectomy. An oxygen source with a flow of $5 \mathrm{Lpm}$ is attached by standard tubing to the suction port of a 4-mm bronchoscope. The bronchoscope is then inserted into the left bronchial lumen of the DLT and guided into the basal segments of the left lower lobe bronchus. (Insert) When the suction trigger of the bronchoscope is activated, oxygen is insufflated into the segments of the lung remote from the site of surgery under direct visual observation by the thoracoscope. In this case, the basal segments of the left lower lobe were recruited and surgery could continue unimpeded on the left upper lobe. (Reproduced from Ku CM, Slinger P, Waddell TK. A novel method of treating hypoxemia during one-lung ventilation for thoracoscopic surgery. J Cardiothorac Vasc Anesth 2009;23(6):851; with permission.)

Oxygen insufflation into the nonventilated lung may have additional benefits. Pfitzner and colleagues ${ }^{53,54}$ have shown that establishing lung isolation before creation of the surgical pneumothorax results in a tidal excursion of around $130 \mathrm{~mL}$ in the nonventilated operative lung. This tidal excursion occurs secondary to the cyclical midline shift initiated by the positive pressure ventilation of the nonoperative lung. These investigators have argued that the tidal excursion of the operative lung leads to nitrogen entrainment, which could delay lung collapse and impair HPV. Several investigators have described ambient pressure oxygen administration devices that create a closed system for the operative lung and have anecdotally reported good results for oxygenation during thoracoscopic surgeries in patients with advanced lung disease. ${ }^{54,55}$ The caveat to these approaches is that have to be used prophylactically at the beginning of the case and that they require close observation to avoid pressurization (both positive or negative) of the operative lung. There has not been any formal evaluation of these techniques.

On rare occasions, lung isolation is not essential and ventilation of a lobe on the operative side may be possible using subsegmental blockade with a bronchial blocker. Diaphragm and lower chest-wall surgery is most likely to be amenable to this. More commonly, particularly for peripheral procedures such as wedge resections, TLV 
and intermittent apnea may be possible. $\mathrm{CO}_{2}$ insufflation with TLV has been shown to be a suitable alternative to lung isolation in the setting of thoracoscopic sympathectomy, ${ }^{56}$ prone esophagectomy ${ }^{57}$ and pediatric VATS. ${ }^{58} \mathrm{CO}_{2}$ insufflation at low pressures (1-2 $\mathrm{mm} \mathrm{Hg}$ ) has also been described as a means of improving exposure in the setting of pediatric OLV. ${ }^{13,58}$ However, $\mathrm{CO}_{2}$ insufflation pressures of $10 \mathrm{~cm} \mathrm{H}_{2} \mathrm{O}$ or more have been shown to be associated with cardiac indices below $2 \mathrm{Lpm} / \mathrm{m}^{2}$ in adult patients. ${ }^{13}$

Another alternative to OLV is two-lung HFJV. HFJV via a single-lumen endotracheal tube has been shown to result in superior oxygenation and equivalent operative conditions for lung resection, esophagectomy, and minimally invasive coronary artery bypass graft (CABG). ${ }^{59-61}$ HFJV has been used on the operative lung for thoracoscopic procedures without adverse effects on surgical exposure. ${ }^{59,62}$ Two-lung HFJV does require a formal automated jet ventilator and a thorough understanding of its use.

In addition, HFJV has been described as a CPAP alternative for patients at high risk for perioperative desaturation during OLV. ${ }^{63-65}$

\section{RISK OF HYPOXIA}

OLV is associated with significant oxidative stress, irrespective of whether hypoxemia does occur. Even in the setting of normoxemia, OLV triggers an ischemia-reperfusion cascade and creates oxidative stress to both the lung and the heart ${ }^{66,67}$ as well as histologic oxidative injury to the liver and the intestinal tract. ${ }^{68}$ The amount of oxidative stress correlates with the duration of OLV and may therefore be increased in the face of prolonged operating times during VATS. Similarly, brain tissue oxygen saturations decrease during OLV even in normoxemic patients. ${ }^{69,70}$ Reduced brain saturations have been associated with increased length of stay and major organ morbidity and mortality after CABG. ${ }^{71}$ Intraoperative hypoxemia is likely to worsen the amount of oxidative stress and the severity of brain desaturations and therefore may adversely affect organ function and patient outcome. Although this is speculative, prolonged hypoxemia is likely to be harmful and should be treated.

Despite our best efforts, and because of the increasing number of patients presenting after previous contralateral resection, some patients may be difficult to oxygenate with the limited options that are available during thoracoscopic procedures. Furthermore, some of the partial ventilation techniques may worsen surgical exposure to the point that surgical progress is slowed and the risk of complications increased. Although a conversion may be undesirable, the morbidity of persistent hypoxemia outweighs that of a thoracotomy incision.

\section{REFERENCES}

1. Conacher ID. Anesthesia for thoracoscopic surgery. J Minim Access Surg 2007; 3(4):127-31.

2. Lee P, Mathur PN, Colt HG. Advances in thoracoscopy: 100 years since Jacobaeus. Respiration 2010;79(3):177-86.

3. Swanson SJ, Meyers BF, Gunnarsson CL, et al. Video-assisted thoracoscopic lobectomy is less costly and morbid than open lobectomy: a retrospective multiinstitutional database analysis. Ann Thorac Surg 2012;93(4):1027-32.

4. Shigemura N, Akashi A, Funaki S, et al. Long-term outcomes after a variety of video-assisted thoracoscopic lobectomy approaches for clinical stage IA lung cancer: a multi-institutional study. J Thorac Cardiovasc Surg 2006;132(3):507-12. 
5. Berry MF, D'Amico TA. Complications of thoracoscopic pulmonary resection. Semin Thorac Cardiovasc Surg 2007;19(4):350-4.

6. Cheng D, Downey RJ, Kernstine K, et al. Video-assisted thoracic surgery in lung cancer resection: a meta-analysis and systematic review of controlled trials. Innovations (Phila) 2007;2(6):261-92.

7. West D, Rashid S, Dunning J. Does video-assisted thoracoscopic lobectomy produce equal cancer clearance compared to open lobectomy for non-small cell carcinoma of the lung? Interact Cardiovasc Thorac Surg 2007;6(1):110-6.

8. Fischer GW, Cohen E. An update on anesthesia for thoracoscopic surgery. Curr Opin Anaesthesiol 2010;23(1):7-11.

9. Lohser J. Evidence-based management of one-lung ventilation. Anesthesiol Clin 2008;26(2):241-72.

10. Ishikawa S, Lohser J. One-lung ventilation and arterial oxygenation. Curr Opin Anaesthesiol 2011;24(1):24-31.

11. Fredman B. Physiologic changes during thoracoscopy. Anesthesiol Clin North America 2001;19(1):141-52.

12. Ko R, McRae K, Darling $G$, et al. The use of air in the inspired gas mixture during two-lung ventilation delays lung collapse during one-lung ventilation. Anesth Analg 2009;108(4):1092-6.

13. Brock H, Rieger R, Gabriel C, et al. Haemodynamic changes during thoracoscopic surgery the effects of one-lung ventilation compared with carbon dioxide insufflation. Anaesthesia 2000;55(1):10-6.

14. Ishikawa S, Shirasawa M, Fujisawa M, et al. Compressing the non-dependent lung during one-lung ventilation improves arterial oxygenation, but impairs systemic oxygen delivery by decreasing cardiac output. J Anesth 2010;24(1):17-23.

15. Tusman G, Böhm SH, Sipmann FS, et al. Lung recruitment improves the efficiency of ventilation and gas exchange during one-lung ventilation anesthesia. Anesth Analg 2004;98(6):1604-9.

16. Unzueta C, Tusman G, Suarez-Sipmann F, et al. Alveolar recruitment improves ventilation during thoracic surgery: a randomized controlled trial. $\mathrm{Br} \mathrm{J}$ Anaesth 2012;108(3):517-24.

17. Cinnella G, Grasso S, Natale C, et al. Physiological effects of a lung-recruiting strategy applied during one-lung ventilation. Acta Anaesthesiol Scand 2008; 52(6):766-75.

18. Garutti I, Martinez G, Cruz P, et al. The impact of lung recruitment on hemodynamics during one-lung ventilation. J Cardiothorac Vasc Anesth 2009;23(4):506-8.

19. Hansen LK, Koefoed-Nielsen J, Nielsen J, et al. Are selective lung recruitment maneuvers hemodynamically safe in severe hypovolemia? An experimental study in hypovolemic pigs with lobar collapse. Anesth Analg 2007;105(3):729-34.

20. Slinger PD, Hickey DR. The interaction between applied PEEP and auto-PEEP during one-lung ventilation. J Cardiothorac Vasc Anesth 1998;12(2):133-6.

21. Bardoczky GI, d'Hollander AA, Cappello M, et al. Interrupted expiratory flow on automatically constructed flow-volume curves may determine the presence of intrinsic positive end-expiratory pressure during one-lung ventilation. Anesth Analg 1998;86(4):880-4.

22. Roberts $\mathrm{DH}$, Lepore $\mathrm{JJ}$, Maroo A, et al. Oxygen therapy improves cardiac index and pulmonary vascular resistance in patients with pulmonary hypertension. Chest 2001;120(5):1547-55.

23. Carlsson AJ, Bindslev L, Hedenstierna G. Hypoxia-induced pulmonary vasoconstriction in the human lung. The effect of isoflurane anesthesia. Anesthesiology 1987;66(3):312-6. 
24. Klima UP, Lee MY, Guerrero JL, et al. Determinants of maximal right ventricular function: role of septal shift. J Thorac Cardiovasc Surg 2002;123(1):72-80.

25. Vlahakes GJ, Turley K, Hoffman JI. The pathophysiology of failure in acute right ventricular hypertension: hemodynamic and biochemical correlations. Circulation 1981;63(1):87-95.

26. Slinger $P$, Scott WA. Arterial oxygenation during one-lung ventilation. A comparison of enflurane and isoflurane. Anesthesiology 1995;82(4):940-6.

27. Russell WJ, James MF. The effects on arterial haemoglobin oxygen saturation and on shunt of increasing cardiac output with dopamine or dobutamine during one-lung ventilation. Anaesth Intensive Care 2004;32(5):644-8.

28. Groves BM, Reeves JT, Sutton JR, et al. Operation Everest II: elevated highaltitude pulmonary resistance unresponsive to oxygen. J Appl Physiol 1987; 63(2):521-30.

29. Ross AF, Ueda K. Pulmonary hypertension in thoracic surgical patients. Curr Opin Anaesthesiol 2010;23(1):25-33.

30. Rich GF, Lowson SM, Johns RA, et al. Inhaled nitric oxide selectively decreases pulmonary vascular resistance without impairing oxygenation during one-lung ventilation in patients undergoing cardiac surgery. Anesthesiology 1994;80(1): 57-62.

31. Moutafis M, Liu N, Dalibon N, et al. The effects of inhaled nitric oxide and its combination with intravenous almitrine on Pao2 during one-lung ventilation in patients undergoing thoracoscopic procedures. Anesth Analg 1997;85(5): 1130-5.

32. Schwarzkopf K, Klein U, Schreiber T, et al. Oxygenation during one-lung ventilation: the effects of inhaled nitric oxide and increasing levels of inspired fraction of oxygen. Anesth Analg 2001;92(4):842-7.

33. Sticher J, Scholz S, Böning O, et al. Small-dose nitric oxide improves oxygenation during one-lung ventilation: an experimental study. Anesth Analg 2002;95(6): 1557-62.

34. Haché M, Denault A, Bélisle S, et al. Inhaled epoprostenol (prostacyclin) and pulmonary hypertension before cardiac surgery. J Thorac Cardiovasc Surg 2003;125(3):642-9.

35. Max M, Kuhlen R, Dembinski R, et al. Effect of aerosolized prostacyclin and inhaled nitric oxide on experimental hypoxic pulmonary hypertension. Intensive Care Med 1999;25(10):1147-54.

36. Khan TA, Schnickel G, Ross D, et al. A prospective, randomized, crossover pilot study of inhaled nitric oxide versus inhaled prostacyclin in heart transplant and lung transplant recipients. J Thorac Cardiovasc Surg 2009;138(6):1417-24.

37. Haché M, Denault AY, Bélisle S, et al. Inhaled prostacyclin (PGI2) is an effective addition to the treatment of pulmonary hypertension and hypoxia in the operating room and intensive care unit. Can J Anaesth 2001;48(9):924-9.

38. Della Rocca G, Coccia C, Pompei L, et al. Inhaled aerosolized prostaglandin E1, pulmonary hemodynamics, and oxygenation during lung transplantation. Minerva Anestesiol 2008;74(11):627-33.

39. De Wet CJ, Affleck DG, Jacobsohn E, et al. Inhaled prostacyclin is safe, effective, and affordable in patients with pulmonary hypertension, right heart dysfunction, and refractory hypoxemia after cardiothoracic surgery. J Thorac Cardiovasc Surg 2004;127(4):1058-67.

40. Moutafis M, Dalibon N, Liu N, et al. The effects of intravenous almitrine on oxygenation and hemodynamics during one-lung ventilation. Anesth Analg 2002;94(4): 830-4. 
41. Silva-Costa-Gomes T, Gallart L, Vallès J, et al. Low- vs high-dose almitrine combined with nitric oxide to prevent hypoxia during open-chest one-lung ventilation. Br J Anaesth 2005;95(3):410-6.

42. Doering EB, Hanson CW, Reily DJ, et al. Improvement in oxygenation by phenylephrine and nitric oxide in patients with adult respiratory distress syndrome. Anesthesiology 1997;87(1):18-25.

43. Watanabe A, Koyanagi T, Nakashima S, et al. How to clamp the main pulmonary artery during video-assisted thoracoscopic surgery lobectomy. Eur J Cardiothorac Surg 2007;31(1):129-31.

44. Kamiyoshihara M, Nagashima $\mathrm{T}$, Ibe $\mathrm{T}$, et al. A tip for controlling the main pulmonary artery during video-assisted thoracic major pulmonary resection: the outside-field vascular clamping technique. Interact Cardiovasc Thorac Surg 2010;11(5):693-5.

45. Cohen E, Eisenkraft JB, Thys DM, et al. Oxygenation and hemodynamic changes during one-lung ventilation: effects of CPAP10, PEEP10, and CPAP10/PEEP10. J Cardiothorac Anesth 1988;2(1):34-40.

46. Badner NH, Goure C, Bennett KE, et al. Role of continuous positive airway pressure to the non-ventilated lung during one-lung ventilation with low tidal volumes. HSR Proc Intensive Care Cardiovasc Anesth 2011;3(3):189-94.

47. Kim SH, Jung KT, An TH. Effects of tidal volume and PEEP on arterial blood gases and pulmonary mechanics during one-lung ventilation. J Anesth 2012;26(4): 568-73.

48. El-Tahan MR, El Ghoneimy YF, Regal MA, et al. Comparative study of the nondependent continuous positive pressure ventilation and high-frequency positivepressure ventilation during one-lung ventilation for video-assisted thoracoscopic surgery. Interact Cardiovasc Thorac Surg 2011;12(6):899-902.

49. Russell WJ. Intermittent positive airway pressure to manage hypoxia during onelung anaesthesia. Anaesth Intensive Care 2009;37(3):432-4.

50. Ku CM, Slinger P, Waddell TK. A novel method of treating hypoxemia during onelung ventilation for thoracoscopic surgery. J Cardiothorac Vasc Anesth 2009; 23(6):850-2.

51. Sanchez-Lorente D, Gómez-Caro A, Jimenez MJ, et al. Apnoeic oxygenation on one-lung ventilation in functionally impaired patients during sleeve lobectomy. Eur J Cardiothorac Surg 2011;39(4):77-9.

52. Slimani J, Russell WJ, Jurisevic C. An evaluation of the relative efficacy of an open airway, an oxygen reservoir and continuous positive airway pressure $5 \mathrm{~cm} \mathrm{H} 2 \mathrm{O}$ on the non-ventilated lung. Anaesth Intensive Care 2004;32(6): 756-60.

53. Pfitzner J, Peacock MJ, McAleer PT. Gas movement in the nonventilated lung at the onset of single-lung ventilation for video-assisted thoracoscopy. Anaesthesia 1999;54(5):437-43.

54. Pfitzner J, Peacock MJ, Daniels BW. Ambient pressure oxygen reservoir apparatus for use during one-lung anaesthesia. Anaesthesia 1999;54(5):454-8.

55. Baraka A, Lteif A, Nawfal M, et al. Ambient pressure oxygenation via the nonventilated lung during video-assisted thoracoscopy. Anaesthesia 2000;55(6):602-3.

56. Rozenberg B, Katz Y, Isserles SA, et al. Near-sitting position and two-lung ventilation for endoscopic transthoracic sympathectomy. J Cardiothorac Vasc Anesth 1996;10(2):210-2.

57. Bonavina L, Laface $L$, Abate $E$, et al. Comparison of ventilation and cardiovascular parameters between prone thoracoscopic and Ivor Lewis esophagectomy. Updates Surg 2012;64(2):81-5. 
58. Gentili A, Lima M, De Rose R, et al. Thoracoscopy in children: anaesthesiological implications and case reports. Minerva Anestesiol 2007;73(3):161-71.

59. Ender J, Brodowsky M, Falk V, et al. High-frequency jet ventilation as an alternative method compared to conventional one-lung ventilation using double-lumen tubes during minimally invasive coronary artery bypass graft surgery. J Cardiothorac Vasc Anesth 2010;24(4):602-7.

60. Buise M, van Bommel J, van Genderen M, et al. Two-lung high-frequency jet ventilation as an alternative ventilation technique during transthoracic esophagectomy. J Cardiothorac Vasc Anesth 2009;23(4):509-12.

61. Misiolek H, Knapik P, Swanevelder J, et al. Comparison of double-lung jet ventilation and one-lung ventilation for thoracotomy. Eur J Anaesthesiol 2008;25(1): 15-21.

62. Suzuki Y, Katori K, Mayama T, et al. Anesthetic management for thoracoscopic partial lobectomy in a patient with one lung. Masui 2002;51(8):921-3 [in Japanese].

63. Knüttgen $\mathrm{D}$, Zeidler $\mathrm{D}$, Vorweg $\mathrm{M}$, et al. Unilateral high-frequency jet ventilation supporting one-lung ventilation during thoracic surgical procedures. Anaesthesist 2001;50(8):585-9 [in German].

64. Knüttgen D, Zeidler D, Doehn M. Secondary lung surgery following contralateral pneumonectomy. Anaesthesiological considerations. Anaesthesist 2003;52(1): 42-6 [in German].

65. Godet G, Bertrand M, Rouby JJ, et al. High-frequency jet ventilation vs continuous positive airway pressure for differential lung ventilation in patients undergoing resection of thoracoabdominal aortic aneurysm. Acta Anaesthesiol Scand 1994;38(6):562-8.

66. Williams EA, Quinlan GJ, Goldstraw P, et al. Postoperative lung injury and oxidative damage in patients undergoing pulmonary resection. Eur Respir J 1998; 11(5):1028-34.

67. Misthos P, Katsaragakis S, Theodorou D, et al. The degree of oxidative stress is associated with major adverse effects after lung resection: a prospective study. Eur J Cardiothorac Surg 2006;29(4):591-5.

68. Yuluğ E, Tekinbas $\mathrm{C}$, Ulusoy $\mathrm{H}$, et al. The effects of oxidative stress on the liver and ileum in rats caused by one-lung ventilation. J Surg Res 2007;139(2):253-60.

69. Hemmerling TM, Bluteau MC, Kazan R, et al. Significant decrease of cerebral oxygen saturation during single-lung ventilation measured using absolute oximetry. Br J Anaesth 2008;101(6):870-5.

70. Iwata M, Inoue S, Kawaguchi M, et al. Jugular bulb venous oxygen saturation during one-lung ventilation under sevoflurane- or propofol-based anesthesia for lung surgery. J Cardiothorac Vasc Anesth 2008;22(1):71-6.

71. Murkin JM, Adams SJ, Novick RJ, et al. Monitoring brain oxygen saturation during coronary bypass surgery: a randomized, prospective study. Anesth Analg 2007; 104(1):51-8. 